Tohoku J. exp. Med., 1974, 112, 339-353

\title{
Causes of death in 3151 Diabetic Autopsy Cases
}

\author{
Yoshio Goto, Shin-IChiro Sato and Mitsuo Masuda \\ Third Department of Internal Medicine, Hirosaki University \\ School of Medicine, Hirosaki
}

\begin{abstract}
Goto, Y., Sato, S. and Masuda, M. Causes of Death in 3151 Diabetic Autopsy Cases. Tohoku J. exp. Med., 1974, 112 (4), 339-353 — The cause of death and the patho-anatomical changes of various organs were analyzed in 3,151 diabetic autopsy cases, which were collected from Annual Reports of Pathological Autopsy Cases (1958-1970) published by the Japanese Society of Pathology. In 2,754 primary diabetics, the causes of death were as follow: diabetic coma $4.5 \%$, arteriosclerotic cardiovascular diseases $41.2 \%$ (renal $19.3 \%$, cerebral $11.1 \%$, coronary $6.5 \%$ ), infections $19.4 \%$ (tuberculosis $4.6 \%$, lung $5.8 \%$, urinary tract $3.3 \%$, biliary tract $1.0 \%$ ), malignant neoplasms $15.9 \%$ (stomach $3.9 \%$, lung $3.7 \%$ ), miscellaneous $15.2 \%$. Diabetic coma was most common in the first decade and decreased with age. Infections were high in the third and fourth decades but showed no tendency to increase with age. Among the infections, the highest was purulent pulmonary disease. The arteriosclerotic cardiovascular disease was not seen in the first and the second decade as the main cause of death. They appeared at the third decade and increased with age. As compared with the reports from American and European countries, a high incidence of diabetic nephropathy and a low incidence of ischemic heart disease are characteristic of this series. As a cause of the low incidence of ischemic heart disease, the low consumption of fat in this country was proposed. Diabetic glomerulosclerosis was high in the third to sixth decades, especially in females. The incidence of cerebral infarction in this diabetic series was significantly higher than that in the general population, but that of cerebral hemorrhage was not different from that in the general population. 397 cases were classified as secondary diabetes (12.6 $\%$ ). These consisted of 96 pancreatic cancer, 25 pancreatitis, 175 liver cirrhosis, 22 hemochromatosis, 16 endocrine diseases and 63 steroid diabetes. cause of death, diabetic complication, diabetic nephropathy, secondary diabetes.
\end{abstract}

The survival duration of diabetic patients has been greatly prolonged by the progress in the treatment. One of the final goals of the diabetes research is to find an ideal method for the treatment. It is necessary for approaching this to know the natural history of the disease including the cause of death.

Several statistical reports have been published on the cause of death in diabetic patients (Fitz and Murphy 1924; Lyon and Lyon 1930; Sevringhaus 1931; Flynn 1935; John 1937; Robbins and Tucker 1944; John 1950; Tobler 1954; Schöffling and Graeve 1956; Bell 1960; Munz 1960; Warren et al. 1966; Goto and Fukuhara 1968; Kessler 1971; Marble et al. 1971). The prevalence of the causes, however, is different not only among the countries but also from era to era, and the comparison of the differences may reveal the factors affecting onset or development, course and prognosis of the disease and give a suggestion for a better manage-

Received for publication, December 12, 1973. 
ment of the patients. The present study was undertaken to review the causes of death and the patho-anatomical findings of the diabetic autopsy cases and to compare the result with those of other countries.

Our previous report dealt with cases whose causes of death were mostly judged by clinical diagnosis, and in a few cases the judgment was made from autopsy findings (Yamagata et al. 1967). The result showed that the first-rank cause of death was cancer of the stomach. However, the figure of another clinic showed that the highest cause was cerebral vascular accident (Kuriki 1973). These results obtained from such modest numbers of cases do not seem to show a general figure and may lead to an erroneous conclusion. Based on these considerations, the present analytical study was made on the autopsy cases reported from all over the country.

\section{Source of Cases and Method}

The Japanese Society of Pathology has published the Annual Report of Pathological Autopsy Cases since 1958. The cases recorded in these Reports were registered from more than two-hundred hospitals all over Japan. The numbers of the registered cases are increasing each year as shown in Table 1. In these Reports, age, sex, occupation, clinical diagnosis, principal autopsy diagnosis, patho-anatomical findings, associated findings and short notes on therapy are described for each case. These Reports, however, have no description on the duration of the disease nor on laboratory findings of the patients.

In this study, cases with diabetes and diabetic findings were collected from the Annual Reports 1958-1970.

The main cause of death was concluded from the autopsy diagnosis with a consideration on other findings. The details of this decision were described in our preliminary report (Goto and Fukuhara 1968). As sometimes it was not easy to decide one cause of death from the limited description of records and there might be a possibility that the true cause of death was distorted by the author's subjective judgement, the patho-anatomical findings at the autopsy were also analyzed.

The diagnosis of diabetic coma or hypoglycemic coma, as the main cause of death, was made on the basis of clinical diagnosis when there was no patho-anatomical findings for death. The diagnosis of deterioration of diabetes, as the main cause of death, was given to the cases who had neither clinical history of diabetic coma nor serious pathoanatomical findings. The cases with pancreatitis, cancer of the pancreas, or various endocrine disorders precipitating diabetes were classified as secondary diabetes. It was not always easy to discriminate whether the diabetic state was primary or secondary, especially in the cases of liver diseases or endocrine disorders. Most of the cases with diabetic glomerular changes were classified as primary, even though they had the disease precipitating diabetic state. Of course, it is well known that the diabetic glomerular changes do appear in the secondary diabetes after the diabetic state continues for a certain period of time. Of the 3,151 collected cases, 2,754 were classified as primary and 397 were grouped as secondary diabetes.

\section{Results}

\section{A. Primary diabetes}

\section{Age and sex distribution of the cases}

The age and the sex distribution of the cases is shown in Table 2. The infant cases (died under fifteen years) were only $25(0.9 \%)$ of the total. Although this does 
TABLE 1. Annual number of the registered cases

\begin{tabular}{crrrrrrr}
\hline & \multicolumn{3}{c}{ Total cases registered } & & \multicolumn{3}{c}{ Primary diabetic cases } \\
\cline { 2 - 3 } \cline { 6 - 8 } & Male & Female & Total & & Male & Female & Total \\
\hline 1958 & 5798 & 3341 & 9139 & & 19 & 20 & 39 \\
1959 & 6073 & 3829 & 9902 & & 20 & 23 & 43 \\
1960 & 6942 & 4013 & 10955 & & 58 & 36 & 94 \\
1961 & 7713 & 4595 & 12308 & & 41 & 40 & 81 \\
1962 & 8521 & 5299 & 13820 & & 58 & 44 & 102 \\
1963 & 8680 & 4797 & 13477 & & 69 & 53 & 122 \\
1964 & 10320 & 6221 & 16541 & & 111 & 77 & 188 \\
1965 & 11929 & 7485 & 19414 & & 90 & 54 & 144 \\
1966 & 11884 & 7213 & 19097 & & 182 & 111 & 293 \\
1967 & 10640 & 7170 & 17810 & & 222 & 144 & 366 \\
1968 & 12429 & 8365 & 20794 & & 199 & 164 & 363 \\
1969 & 15000 & 10119 & 25119 & 260 & 219 & 479 \\
1970 & 14198 & 9642 & 23840 & & 253 & 187 & 440 \\
$1958-70$ & 130127 & 82089 & 212216 & & 1582 & 1172 & 2754 \\
\hline
\end{tabular}

TABLE 2. Age and sex distribution of primary diabetic cases

\begin{tabular}{|c|c|c|c|c|c|c|}
\hline \multirow{2}{*}{ Age } & \multicolumn{2}{|c|}{ Male } & \multicolumn{2}{|c|}{ Female } & \multicolumn{2}{|c|}{ Total } \\
\hline & Number & $\%$ & Number & $\%$ & Number & $\%$ \\
\hline-9 & 5 & 0.3 & 2 & 0.2 & 7 & 0.2 \\
\hline $10-19$ & 15 & 1.0 & 20 & 1.7 & 35 & 1.3 \\
\hline $20-29$ & 37 & 2.3 & 51 & 4.4 & 88 & 3.2 \\
\hline $30-39$ & 68 & 4.3 & 67 & 5.7 & 135 & 4.9 \\
\hline $40-49$ & 138 & 8.7 & 121 & 10.3 & 259 & 9.4 \\
\hline $50-59$ & 327 & 23.5 & 243 & 20.7 & 615 & 22.3 \\
\hline $60-69$ & 588 & 37.2 & 424 & 36.2 & 1012 & 36.8 \\
\hline $70-79$ & 304 & 19.2 & 210 & 17.9 & 514 & 18.7 \\
\hline $80-89$ & 54 & 3.4 & 32 & 2.7 & 86 & 3.1 \\
\hline $90-$ & 1 & 0.1 & 2 & 0.2 & 3 & 0.1 \\
\hline Total & 1582 & 100.0 & 1172 & 100.0 & 2754 & 100.0 \\
\hline
\end{tabular}

not always show the exact figure of the infant diabetes, it can easily be understood from the figure that the infant diabetes is relatively rare in this country. The age distribution of the onset of diabetes was described in our previous paper (Goto 1973) and the tendency was very similar to that of this series. The absolute number of male cases was smaller than that of female cases in the second, third and tenth decades and in the other decades the male cases were greater than the female. The percentage in the total registered cases, however, was greater in females than in males (Table 1). The male to female ratio for the percentage was $1: 1.17$.

\section{The cause of death}

The causes of death were classified into seven main categories, i.e. diabetic coma, aggravation of diabetes, iatrogenic hypoglycemia, arteriosclerotic cardiovascular disease, infection, malignant neoplasma and miscellaneous. 
Table 3. Cause of death in diabetic

\begin{tabular}{|c|c|c|c|c|c|c|c|c|c|c|c|c|}
\hline \multirow{2}{*}{$\frac{\text { Age }}{\text { Sex }}$} & \multicolumn{2}{|c|}{$0-9$} & \multicolumn{2}{|c|}{$10-19$} & \multicolumn{2}{|c|}{$20-29$} & \multicolumn{2}{|c|}{$30-39$} & \multicolumn{2}{|c|}{$40-49$} & \multicolumn{2}{|c|}{$50-59$} \\
\hline & M & $\mathrm{F}$ & M & $\mathrm{F}$ & M & $\mathbf{F}$ & M & $F$ & M & $\mathbf{F}$ & M. & $\mathbf{F}$ \\
\hline Number & 5 & 2 & 15 & 20 & 37 & 51 & 68 & 67 & 138 & 121 & 372 & 243 \\
\hline Diabetic coma & 3 & 2 & 10 & 9 & 7 & 10 & 1 & 11 & 5 & 13 & 7 & 10 \\
\hline $\begin{array}{l}\text { Aggravation of } \\
\text { diabetes }\end{array}$ & 1 & & 2 & 8 & 8 & 6 & 6 & 3 & 4 & 9 & 3 & 13 \\
\hline Hypoglycemia & & & & & & 1 & & 1 & 3 & 2 & 4 & $\mathbf{5}$ \\
\hline $\begin{array}{l}\text { Arteriosclerosis } \\
\text { general }\end{array}$ & & & & & 8 & 19 & 24 & 27 & 40 & 46 & $\begin{array}{r}150 \\
5\end{array}$ & $\begin{array}{r}91 \\
4\end{array}$ \\
\hline renal (diabetic) & & & & & 7 & 18 & 23 & 23 & 26 & 39 & 91 & 53 \\
\hline cerebral & & & & & 1 & 1 & 1 & 3 & 10 & 4 & 37 & 23 \\
\hline coronary & & & & & & & & & 3 & 3 & 16 & 10 \\
\hline gangrene & & & & & & & & 1 & 1 & & 1 & 1 \\
\hline Infection & 1 & & 1 & 2 & 6 & 13 & 14 & 13 & 42 & 13 & 72 & 47 \\
\hline tuberculosis & & & & & & 5 & 4 & 2 & 15 & 2 & 27 & 9 \\
\hline pneumonia etc. & 1 & & 1 & 1 & 3 & 3 & 2 & 2 & 13 & 2 & 18 & 10 \\
\hline urinary tract & & & & 1 & 2 & 1 & 1 & 7 & 2 & 7 & 5 & 16 \\
\hline liver, biliary & & & & & & 1 & & & 1 & & 2 & 3 \\
\hline peritonitis & & & & & & & 2 & 1 & 3 & 1 & 8 & 3 \\
\hline sepsis & & & & & & 2 & 4 & 1 & 5 & 1 & 4 & 1 \\
\hline miscellaneous & & & & & 1 & 1 & 1 & & 3 & & 8 & 5 \\
\hline \multicolumn{13}{|l|}{ Malignant } \\
\hline neoplasma & & & & & 2 & & 3 & 2 & 20 & 10 & 68 & 33 \\
\hline stomach & & & & & & & & 1 & 4 & 1 & 18 & 5 \\
\hline lung & & & & & & & & & 5 & 1 & 13 & 3 \\
\hline liver, biliary & & & & & & & 1 & & 5 & 2 & 11 & 3 \\
\hline esophagus & & & & & & & & & & & 4 & \\
\hline colon, rectum & & & & & & & & & & & 2 & 2 \\
\hline uterus, ovary & & & & & & & & & & 2 & & 9 \\
\hline miscellaneous & & & & & 2 & & 2 & 1 & 6 & 4 & 20 & 11 \\
\hline & & & & & 5 & & & & & & & \\
\hline Miscellaneous & & & 2 & 1 & 6 & 2 & 20 & 10 & 24 & 28 & 68 & 44 \\
\hline papill. necrosis & & & & & & & & 1 & 1 & 1 & 1 & 3 \\
\hline Schrumpfniere & & & & & 1 & & 1 & 2 & 3 & 1 & 13 & 9 \\
\hline $\begin{array}{l}\text { glomerulo* } \\
\text { nephritis }\end{array}$ & & & & & & & 4 & 1 & 3 & 4 & 7 & 4 \\
\hline hepatitis & & & & & & & & & 1 & 5 & 8 & 3 \\
\hline liver cirrhosis & & & & & & & 6 & 1 & 3 & & 11 & 6 \\
\hline pancreatitis & & & & & & & 3 & 1 & 5 & 2 & 3 & 2 \\
\hline gast. duod. ulcer & & & & & & 1 & 3 & & 1 & $\overline{1}$ & 5 & 1 \\
\hline heart disease & & & & & & & & & 2 & 3 & 3 & 2 \\
\hline lung disease & & & & & & 1 & 1 & & 1 & 2 & 5 & \\
\hline neuro-, muscular & & & & & & & 1 & & 2 & 2 & 1 & 1 \\
\hline blood disorder & & & & & 1 & & & & & & 3 & 2 \\
\hline intoxication & & & & & & & & & & & 2 & 1 \\
\hline operation & & & & & 1 & & & & 1 & 1 & , & \\
\hline suicide & & & & 1 & & & 1 & & & 2 & " & 2 \\
\hline $\begin{array}{l}\text { intestinal dis. } \\
\text { endocrine dis. } \\
\text { nephrosis }\end{array}$ & & & & & & & & & & 1 & 1 & 1 \\
\hline miscellaneous & & & 1 & & 2 & & & 3 & 1 & 3 & 5 & 7 \\
\hline
\end{tabular}

Figures in parentheses indicate percentage. 
autopsy cases by age group

\begin{tabular}{|c|c|c|c|c|c|c|c|c|c|c|}
\hline \multicolumn{2}{|c|}{$60-69$} & \multicolumn{2}{|c|}{$70-79$} & \multicolumn{2}{|c|}{$80-89$} & \multicolumn{2}{|c|}{$90-$} & \multicolumn{3}{|c|}{ Total } \\
\hline $\mathbf{M}$ & $\mathbf{F}$ & M & $\mathbf{F}$ & M & $\mathbf{F}$ & M & $F$ & Male & Female & Total \\
\hline 588 & 424 & 304 & 210 & 54 & 32 & 1 & 2 & 1582 & 1172 & 2754 \\
\hline 10 & 16 & 2 & 8 & & & & 1 & $45(2.84)$ & $80(6.82)$ & $125(4.54)^{\%}$ \\
\hline 7 & 6 & 1 & 2 & & & & & $32(2.02)$ & $47(4.01)$ & $79(2.87)$ \\
\hline 5 & & 1 & & & & & & $13(0.82)$ & $9(0.77)$ & $22(0.80)$ \\
\hline 256 & 200 & 131 & 104 & 23 & 14 & & 1 & 632(39. 95) & $502(42.83)$ & $1134(41.18)$ \\
\hline 27 & 26 & 22 & 13 & 4 & 8 & & & $58(3.67)$ & $51(4.35)$ & $109(3.96)$ \\
\hline 102 & 77 & 31 & 35 & 5 & & & 1 & $285(18.01)$ & $246(20.99)$ & $531(19.28)$ \\
\hline 70 & 51 & 51 & 39 & 12 & 3 & & & $182(11.50)$ & $124(10.58)$ & $306(11.11)$ \\
\hline 54 & 46 & 27 & 15 & 2 & 3 & & & $102(6.45)$ & $77(6.57)$ & $179(6.50)$ \\
\hline 3 & & & 2 & & & & & $5(0.32)$ & $4(0.34)$ & $9(0.33)$ \\
\hline 99 & 89 & 56 & 41 & 16 & 11 & & & $307(19.41)$ & $239(19.54)$ & $536(19.46)$ \\
\hline 28 & 16 & 11 & 5 & 2 & 1 & & & $87(5.50)$ & $40(3.41)$ & $127(4.61)$ \\
\hline 24 & 25 & 26 & 14 & 11 & 5 & & & $99(6.26)$ & $62(5.29)$ & $161(5.85)$ \\
\hline 9 & 21 & 7 & 12 & 1 & 1 & & & $27(1.71)$ & $66(5.63)$ & $93(3.38)$ \\
\hline 10 & 4 & 5 & 2 & & 1 & & & $18(1.14)$ & $11(0.94)$ & $29(1.05)$ \\
\hline 14 & 2 & 5 & 5 & 1 & & & & $33(2,09)$ & $12(1.02)$ & $45(1.63)$ \\
\hline 8 & 8 & 1 & 3 & 1 & 2 & & & $23(1.45)$ & $18(1.54)$ & $41(1.49)$ \\
\hline 6 & 13 & 1 & & & 1 & & & $20(1.26)$ & $20(1.71)$ & $40(1.45)$ \\
\hline 128 & 57 & 78 & 28 & 9 & 1 & & & $308(19.47)$ & $131(11.18)$ & $439(15.94)$ \\
\hline 35 & 13 & 23 & 6 & 3 & & & & $83(5.25)$ & $26(2.22)$ & $109(3.96)$ \\
\hline 42 & 11 & 20 & 4 & 3 & 1 & & & $83(5.25)$ & $20(1.71)$ & $103(3.74)$ \\
\hline 17 & 11 & 8 & 5 & & & & & $42(2.65)$ & $21(1.79)$ & $63(2.29)$ \\
\hline 8 & & 4 & 1 & & & & & $16(1.01)$ & $1(0.09)$ & $17(0.62)$ \\
\hline 7 & 3 & 7 & 2 & 2 & & & & $18(1.14)$ & $7(0.60)$ & $25(0.91)$ \\
\hline & 10 & & 2 & & & & & & $23(1.96)$ & $23(0.83)$ \\
\hline 19 & 9 & 16 & 8 & 1 & & & & $66(4.17)$ & $33(2.81)$ & $99(3.59)$ \\
\hline 83 & $\begin{array}{r}56 \\
3\end{array}$ & 35 & $\begin{array}{r}27 \\
3\end{array}$ & 6 & 6 & $\begin{array}{l}1 \\
1\end{array}$ & & $\begin{array}{r}245(15.49) \\
3(0.19)\end{array}$ & $\begin{array}{r}174(14.85) \\
11(0.94)\end{array}$ & $\begin{array}{r}419(15.21) \\
14(0.51)\end{array}$ \\
\hline 11 & 10 & 4 & & & 1 & & & $33(2.08)$ & $23(1.96)$ & $56(2.03)$ \\
\hline 8 & 1 & 2 & 4 & & & & & $25(1.58)$ & $14(1,19)$ & $39(1.42)$ \\
\hline 3 & 5 & 3 & 2 & 1 & & & & $17(1.07)$ & $15(1.28)$ & $32(1.16)$ \\
\hline 17 & 3 & 4 & & & & & & $41(2.59)$ & $10(0.85)$ & $51(1.85)$ \\
\hline 1 & 3 & & 2 & 1 & 1 & & & $13(0.82)$ & $11(0.94)$ & $24(0.87)$ \\
\hline 11 & 4 & 7 & 7 & 1 & & & & $28(1.77)$ & $14(1,19)$ & $42(1.52)$ \\
\hline 1 & 6 & 2 & & & 2 & & & $8(0.51)$ & $13(1.11)$ & $21(0.76)$ \\
\hline 9 & 6 & 3 & 2 & 2 & 1 & & & $21(1.33)$ & $13(1.11)$ & $34(1.23)$ \\
\hline 4 & 1 & & & & & & & $8(0.51)$ & $4(0.34)$ & $12(0.44)$ \\
\hline 3 & 5 & 2 & & & & & & $9(0.57)$ & $7(0.60)$ & $16(0.58)$ \\
\hline & & & & & & & & $2(0.13)$ & $1(0.09)$ & $3(0.11)$ \\
\hline 3 & & 1 & & 1 & & & & $7(0.44)$ & $1(0.09)$ & $8(0.29)$ \\
\hline 1 & 1 & & 2 & & & & & $2(0.13)$ & $8(0.68)$ & $10(0.36)$ \\
\hline 1 & 2 & & 2 & & & & & $1(0.06)$ & $4(0.34)$ & $5(0.18)$ \\
\hline 1 & & & & & & & & $2(0.13)$ & $2(0.17)$ & $4(0.15)$ \\
\hline & 1 & & & & & & & & $1(0.09)$ & $1(0.04)$ \\
\hline 9 & 5 & 7 & 3 & & 1 & & & $25(1.58)$ & $22(1.18)$ & $47(1.71)$ \\
\hline
\end{tabular}




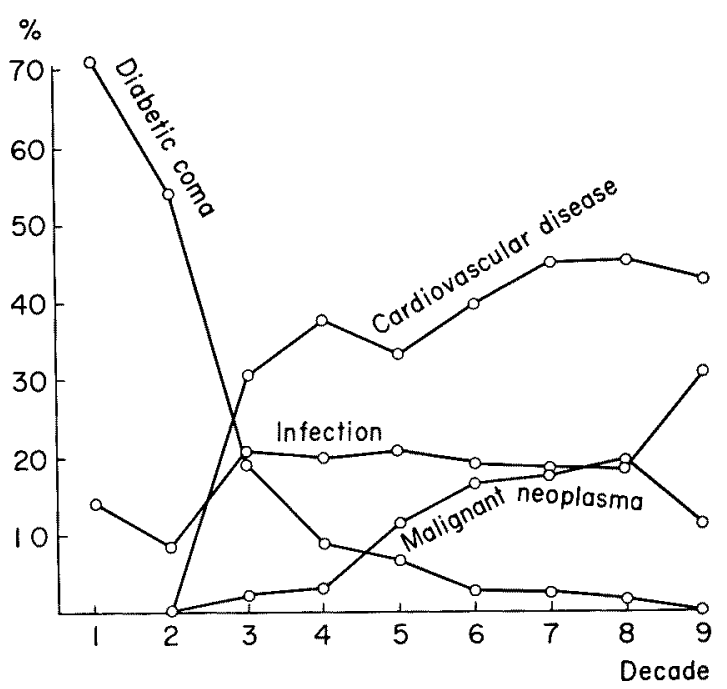

Fig. 1. Incidence of causes of death in diabetic autopsy cases by age group.

As shown in Table 3, the first ranking cause of death was the cardiovascular disorder and it was followed by infection, neoplasma and the coma. The changes in the prevalence of causes of death by age group are depicted in Fig. 1. The diabetic coma was most common in the first decade and it decreased with age. The infection was high in the third and fourth decades but showed no tendency to increase with age.

The arteriosclerotic cardiovascular disease was not seen in the first and the second decade as the main cause of death. It appeared at the third decade and increased with age. Among the cardiovascular diseases, the highest was the diabetic glomerulosclerosis $(19.2 \%)$ and the next was cerebral vascular disease $(11.1 \%)$. Ischemic heart disease held $6.5 \%$ of the total. This figure is quite low as compared with that in the United States, where the ischemic heart disease takes the highest (Bell 1960; Warren et al. 1966).

The first ranking disease in the infection was purulent pulmonary infection. Pulmonary tuberculosis was the most common cause of death until the discovery of streptomycin and it decreased abruptly during the last twenty years. The death of pulmonary tuberculosis was $15.3 \%$ of the cases in 1958 , whereas it was $1.6 \%$ of the cases in 1970. Pulmonary tuberculosis was higher in males than in females.

The urinary tract infection was three times higher in females than in males. Purulent infection of the liver and the biliary tract, peritonitis and sepsis were also high in diabetes.

The neoplasma appeared in the third decade and high precedence was seen from the sixth to eighth decade. In the neoplasma, gastric carcinoma was the highest (3.9\% of all cases) and the second was pulmonary carcinoma (3.7\%). Both were frequent in male cases. The ratio of gastric to pulmonary cancer was 1.28:1 and this seems to be small, as gastric cancer is more common than pulmonary 

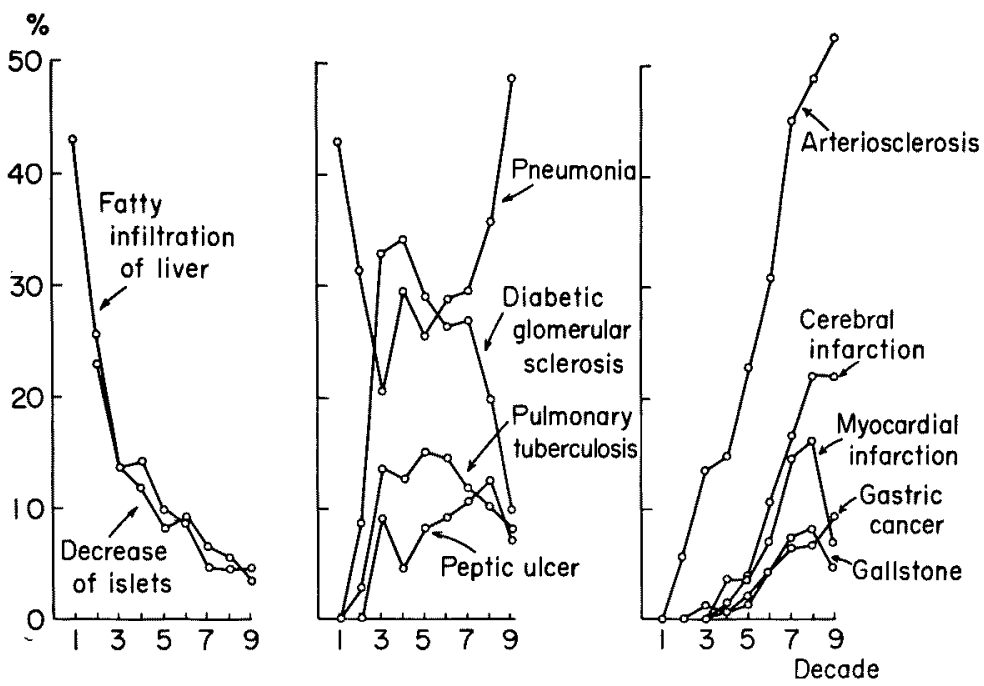

Fig. 2. Incidence of patho-anatomical findings in diabetic autopsy cases by age group.

cancer in general population.

Among the miscellaneous group, the highest was Schrumpfniere and it was followed by liver cirrhosis, ulcer of the stomach and the duodenum, glomerulonephritis, various pulmonary diseases, hepatitis, etc. Renal papillary necrosis was $0.51 \%$ and this was as many as five times more frequent in females than in males.

\section{Autopsy findings}

The patho-anatomical findings are summarized by age and sex in Table 4 and some of them are shown in Fig. 2. Cerebral infarction (or encephalomalacia) was about three times more frequent than cerebral hemorrhage. The infarction increased with age and it was seen in $13.4 \%$ of the total male cases and in $14.4 \%$ of the female cases. Of course, the cerebral arteriosclerosis increased with age.

Inflammation of the thyroid gland was seen in $0.6 \%$ and it was higher in the female cases. Struma was present in $2.5 \%$.

Myocardial infarction was present in $10.7 \%$. As mentioned above, this figure is extremely low in comparison with that in the United States. Arteriosclerosis began to appear at the second decade and increased with age.

Pneumonia and bronchitis were the most frequent findings in the diabetic autopsy cases. They were more frequent in males. Tuberculosis was relatively low in the younger groups and became higher in the older groups. This seemed to be due to the fact that people suffering from tuberculosis were more common in older generation.

The percentages of the carcinomas of the gastro-intestinal tracts were higher in males than in females and this tendency was more clear in cancer of the esophagus and the colon. Ulcer of the stomach and the duodenum was less frequent in the female cases but ulcer of the colon was more frequent in the female. 
TABLE 4. Patho-anatomical findings

\begin{tabular}{|c|c|c|c|c|c|c|c|c|c|c|}
\hline \multirow{2}{*}{$\begin{array}{c}\text { Age } \\
\text { Sex }\end{array}$} & \multicolumn{2}{|c|}{$0-9$} & \multicolumn{2}{|c|}{$10-19$} & \multicolumn{2}{|c|}{$20-29$} & \multicolumn{2}{|c|}{ 30-39 } & \multicolumn{2}{|c|}{$40-49$} \\
\hline & $\mathbf{M}$ & $\mathbf{F}$ & M & $\mathbf{F}$ & $\mathrm{M}$ & $\mathbf{F}$ & $\mathbf{M}$ & $\mathbf{F}$ & $\mathbf{M}$ & $\mathbf{F}$ \\
\hline Number & 5 & 2 & 15 & 20 & 37 & 51 & 68 & 67 & 138 & 121 \\
\hline Cerebral edema & 1 & 1 & 1 & 4 & 6 & 1 & 2 & 1 & 3 & 3 \\
\hline Cerebral hemorrhage & & & 1 & 1 & 3 & & 1 & 5 & 6 & 3 \\
\hline Cerebral infarction & & & & 1 & & & & 2 & 5 & 5 \\
\hline Brain tumor & & & & 1 & 1 & & 1 & 1 & 3 & 1 \\
\hline Cerebral arteriosclerosis & & & & & & & & & 2 & 2 \\
\hline Atrophy of hypophysis & & & 1 & & & & & 1 & 3 & 1 \\
\hline Pituitary adenoma & & & & & & & & 1 & & \\
\hline Strumitis & & & & 2 & & & 2 & & & \\
\hline Struma & & & & 1 & & & 3 & 1 & 2 & 4 \\
\hline Cancer of thyroid & & & & & & & & & 3 & \\
\hline Atrophy of thyroid & & & 1 & 1 & & 1 & & 1 & 1 & 1 \\
\hline Cardiac hypertrophy & & 1 & & 1 & & 8 & 13 & 16 & 33 & 30 \\
\hline Myocardial infarotion & & & & & & & 1 & 4 & 4 & 6 \\
\hline Coronary sclerosis & & & & & & 2 & 2 & 1 & 5 & 3 \\
\hline Arteriosclerosis (general) & & & 1 & 1 & 1 & 11 & 10 & 10 & 34 & 25 \\
\hline Arterial thrombosis & & & & & 1 & & 1 & & 4 & 1 \\
\hline Aortic aneurysm & & & 1 & & & & & & & \\
\hline Pneumonia, bronchitis & 3 & & 6 & 5 & 9 & 9 & 20 & 20 & 37 & 29 \\
\hline Pulmonary tuberculosis & & & 1 & & 4 & 8 & 10 & 7 & 28 & 11 \\
\hline Pulmonary emphysema & & 1 & 1 & & 2 & & & 1 & 2 & \\
\hline Pulmonary edema & 2 & & 2 & 6 & 7 & 8 & 11 & 9 & 18 & 16 \\
\hline Pulmonary fibrosis & & & & & & & & & 1 & \\
\hline Cancer of lung, bronchus & & & & & & & 1 & & 3 & 1 \\
\hline Pleuritis & & & & & & 2 & 4 & 2 & 10 & 3 \\
\hline \multicolumn{11}{|l|}{$\begin{array}{l}\text { Cancer of esophagus and } \\
\text { pharynx }\end{array}$} \\
\hline Esophageal varices & & & & & & & 5 & & 2 & \\
\hline Gastr. duod. ulcer & & & & & 3 & 5 & 6 & & 12 & 9 \\
\hline Gastric cancer & & & & & & & & 1 & 4 & 1 \\
\hline \multirow{2}{*}{\multicolumn{11}{|c|}{$\begin{array}{l}\text { Colon, rectal ulcer } \\
\text { Cancer of colon and rectum }\end{array}$}} \\
\hline & & & & & & & & & & \\
\hline Fatty infiltration of liver & 1 & 2 & 5 & 4 & 5 & 7 & 8 & 11 & 13 & 12 \\
\hline Liver abcess & & & & & & 1 & & & 3 & 1 \\
\hline Hepatitis & & & & 1 & 1 & 1 & & 2 & 2 & 8 \\
\hline Liver cirrhosis & & & & & 1 & & 11 & 1 & 14 & 4 \\
\hline Fibrosis of liver & & & & 1 & & & & & 5 & 1 \\
\hline Liver enlargement & & & & 3 & 2 & 3 & 4 & 2 & 4 & 3 \\
\hline Glycogen degener. of liver & & & & 4 & & & 1 & 1 & 3 & 1 \\
\hline Hepatic cancer & & & & & & & & & 4 & \\
\hline Cholecystitis, Cholangitis & & & & & & 2 & & 1 & 1 & 2 \\
\hline Stone of biliary system & & & & & & 1 & & 1 & 2 & 2 \\
\hline $\begin{array}{l}\text { Cancer of gall bladder and } \\
\text { choledochus }\end{array}$ & & & & & & & 1 & & 2 & 2 \\
\hline Atrophy of pancreas & & 2 & 3 & 5 & 9 & 12 & 12 & 10 & 27 & 26 \\
\hline Fatty infltr. of pancreas & & & 1 & & & & & 1 & 4 & 2 \\
\hline Pancreatitis & & & & & & 1 & 5 & 7 & 10 & 6 \\
\hline Fibrosis of pancreas & & & & & & $\overline{1}$ & 2 & 2 & 6 & 8 \\
\hline Pancreatic cirrhosis & & & & 1 & 1 & 1 & 1 & 2 & 2 & \\
\hline
\end{tabular}


in diabetic autopsy cases

\begin{tabular}{|c|c|c|c|c|c|c|c|c|c|c|c|c|}
\hline \multicolumn{2}{|c|}{$50-59$} & \multicolumn{2}{|c|}{$60-69$} & \multicolumn{2}{|c|}{$70-79$} & \multicolumn{2}{|c|}{$80-89$} & \multicolumn{2}{|c|}{$90-$} & \multicolumn{3}{|c|}{ Total } \\
\hline M & $\mathbf{F}$ & M & $\mathbf{F}$ & M & $\mathbf{F}$ & $\mathbf{M}$ & F & $\mathbf{M}$ & $\mathbf{F}$ & Male & Female & Total \\
\hline 372 & 243 & 588 & 424 & 304 & 210 & 54 & 32 & 1 & 2 & 1582 & 1172 & 2754 \\
\hline 7 & 6 & 11 & 9 & 8 & 5 & & 1 & & & 39 & 31 & 70 \\
\hline 37 & 13 & 24 & 31 & 19 & 6 & 6 & 1 & & & 97 & 60 & 157 \\
\hline 40 & 26 & 88 & 80 & 67 & 47 & 11 & 8 & 2 & & 213 & 169 & 382 \\
\hline 13 & 6 & 8 & 11 & 1 & 1 & & & 1 & & 28 & 21 & 49 \\
\hline 13 & 8 & 26 & 24 & 15 & 16 & 4 & 4 & & & 60 & 54 & 114 \\
\hline 2 & & 2 & 2 & 1 & & & & & & 9 & 4 & 13 \\
\hline & & & & & 1 & I & & & & 1 & 2 & 3 \\
\hline 1 & & 3 & 6 & & 3 & & 1 & & & 6 & 12 & 18 \\
\hline 9 & 11 & 9 & 18 & 2 & 6 & 1 & 3 & & & 27 & 44 & 71 \\
\hline 1 & 2 & 3 & 1 & & 3 & & & & & 7 & 6 & 13 \\
\hline 3 & & 2 & 1 & 2 & 2 & & & & & 9 & 7 & 16 \\
\hline 122 & 60 & 170 & 102 & 84 & 63 & 13 & 11 & & 2 & 442 & 294 & 736 \\
\hline 27 & 16 & 85 & 63 & 53 & 30 & 4 & 2 & & 1 & 174 & 122 & 296 \\
\hline 26 & 16 & 48 & 41 & 26 & 20 & 5 & 2 & & 1 & 112 & 86 & 198 \\
\hline 120 & 70 & 270 & 187 & 153 & 99 & 29 & 17 & & 1 & 618 & 421 & 1039 \\
\hline 1 & 2 & 7 & 6 & 1 & 8 & & 2 & & & 15 & 19 & 34 \\
\hline & & 5 & & 6 & 2 & & $\overrightarrow{1}$ & & & 12 & 3 & 15 \\
\hline 107 & 71 & 186 & 115 & 117 & 67 & 31 & 11 & 1 & & 517 & 327 & 844 \\
\hline 66 & 24 & 78 & 42 & 43 & 14 & 4 & 3 & & & 234 & 109 & 343 \\
\hline 11 & 7 & 38 & 9 & 18 & 6 & 7 & 3 & & & 79 & 27 & 106 \\
\hline 50 & 39 & 65 & 50 & 43 & 30 & 6 & & & & 204 & 158 & 362 \\
\hline & 1 & 6 & 8 & 4 & 4 & & & & & 11 & 13 & 24 \\
\hline 13 & 3 & 40 & 13 & 23 & 5 & 3 & 1 & & & 83 & 23 & 106 \\
\hline 26 & 11 & 38 & 22 & 12 & 12 & 6 & 1 & & & 97 & 53 & 150 \\
\hline 6 & & 7 & & 6 & 1 & 2 & & & & 21 & 1 & 22 \\
\hline 10 & 1 & 10 & 2 & & 1 & & & & & 27 & 4 & 31 \\
\hline 44 & 12 & 71 & 35 & 36 & 28 & 4 & 2 & & & 176 & 91 & $2^{67}$ \\
\hline 19 & 7 & 43 & 19 & 27 & 7 & 7 & 1 & & & 100 & 36 & 136 \\
\hline 2 & 3 & 1 & 2 & 2 & 1 & & 1 & & & 5 & 7 & 12 \\
\hline 2 & 1 & 11 & 4 & 8 & 2 & 2 & & & & 23 & 7 & 30 \\
\hline 21 & 32 & 23 & 24 & 11 & 12 & 4 & & & & 91 & 104 & 195 \\
\hline & 7 & 14 & 2 & 6 & 2 & 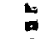 & 1 & & & 23 & 14 & 37 \\
\hline 16 & 4 & 18 & 12 & 9 & 4 & 2 & & & & 48 & 32 & 80 \\
\hline 49 & 16 & 52 & 23 & 16 & 9 & & 1 & & & 143 & 54 & 197 \\
\hline 11 & 2 & 13 & 5 & 5 & 4 & 1 & & & L & 35 & 14 & 49 \\
\hline 7 & 3 & 10 & 7 & 2 & & 1 & & & & 30 & 21 & 51 \\
\hline 2 & 3 & 2 & 5 & & 2 & & & & & 8 & 16 & 24 \\
\hline 8 & & 14 & 1 & 2 & 3 & & & & & 28 & 4 & 32 \\
\hline 6 & 5 & 28 & 10 & 8 & 10 & & 3 & & & 43 & 33 & 76 \\
\hline 11 & 15 & 38 & 36 & 21 & 21 & 1 & 3 & & & 73 & 79 & 152 \\
\hline 4 & 3 & 11 & 10 & 6 & 5 & & & & & 24 & 20 & 44 \\
\hline 45 & 64 & 85 & 94 & 48 & 45 & 8 & 5 & & 1 & 238 & 264 & 502 \\
\hline 2 & 4 & 14 & 9 & 14 & 5 & 1 & 1 & & & 36 & 22 & 58 \\
\hline 15 & 9 & 25 & 15 & 9 & 8 & 1 & 1 & & & 65 & 47 & 112 \\
\hline 13 & 10 & 18 & 13 & 4 & 7 & 3 & & & & 46 & 41 & 87 \\
\hline 6 & 2 & 8 & 4 & 6 & 2 & & & & & 24 & 12 & 36 \\
\hline
\end{tabular}


Table 4. (Continued)

\begin{tabular}{|c|c|c|c|c|c|c|c|c|c|c|}
\hline \multirow{2}{*}{$\frac{\text { Age }}{\text { Sex }}$} & \multicolumn{2}{|c|}{$0-9$} & \multicolumn{2}{|c|}{$10-19$} & \multicolumn{2}{|c|}{$20-29$} & \multicolumn{2}{|c|}{$30-39$} & \multicolumn{2}{|c|}{$40-49$} \\
\hline & M & $\mathbf{F}$ & M & $\mathbf{F}$ & M & $\mathbf{F}$ & $\mathbf{M}$ & $\mathbf{F}$ & $\mathbf{M}$ & $\mathbf{F}$ \\
\hline Number & 5 & 2 & 15 & 20 & 37 & 51 & 68 & 67 & 138 & 121 \\
\hline \multicolumn{11}{|l|}{ Cancer of pancreas } \\
\hline Decrease, atrophy of islets & & & 5 & 3 & 4 & 8 & 5 & 11 & 13 & 8 \\
\hline Hypertrophy of islets & & & & 1 & 1 & 1 & & & & 2 \\
\hline Edema of islets & & & & & 1 & & & 2 & & \\
\hline Fibrosis of islets & & & & 2 & 1 & 1 & 1 & & & 1 \\
\hline Hyaline degenerat. of islets & & & & & 1 & 1 & 3 & 2 & 5 & 7 \\
\hline \multicolumn{11}{|l|}{ Amyloidosis of islets } \\
\hline Atrophy of spleen & & & & & 1 & & & 1 & 1 & 4 \\
\hline Splenomegaly & & & & 2 & 1 & 1 & 6 & 2 & 8 & 8 \\
\hline Nephrosis & & & & 2 & 1 & 3 & 1 & 4 & 3 & 3 \\
\hline Glomerulonephritis & & & 1 & 2 & 1 & 2 & 6 & 1 & 6 & 8 \\
\hline Renal abcess & & & & & & 2 & 4 & & 5 & 5 \\
\hline Renal infarction & & & & 1 & & & & 2 & 1 & 1 \\
\hline Nephrosclerosis & & & 1 & 1 & 2 & 8 & 12 & 16 & 22 & 22 \\
\hline Schrumpfniere & & & 1 & 1 & 2 & 1 & 1 & 1 & 5 & 8 \\
\hline Diabetic glomerulosclerosis & & & & 3 & 10 & 19 & 25 & 21 & 36 & 39 \\
\hline Papillary necrosis & & & & & & 2 & & 4 & 1 & 2 \\
\hline Pyelonephritis & & & & 1 & 3 & 10 & 4 & 15 & 4 & 18 \\
\hline Hydronephrosis & & & & 1 & & 1 & & & 2 & \\
\hline Renal arterioselerosis & & & & 1 & & & 3 & 2 & 5 & 1 \\
\hline Renal stone & & & & & & & & & & 1 \\
\hline \multicolumn{11}{|l|}{ Cancer of kidney } \\
\hline Urocystitis & & & & & & 5 & 3 & 11 & 1 & 18 \\
\hline \multicolumn{11}{|l|}{ Cancer of urinary bladder } \\
\hline Atrophy of adrenal gland & & & 1 & 2 & 2 & 3 & & 2 & 9 & 2 \\
\hline Hypertrophy of adrenal & & & & & 1 & & & 2 & & 1 \\
\hline Adenoma of adrenal & & & & & & & & 1 & & 1 \\
\hline Prostatitis & & & & & & & & & 1 & \\
\hline Prostatic hypertrophy & & & & & & & 1 & & 3 & \\
\hline Prostatic cancer & & & & & & & 1 & & 1 & \\
\hline \multicolumn{11}{|l|}{ Cancer of uterus } \\
\hline Myoma of uterus & & & & & & & & 3 & & 4 \\
\hline Ovarian cystoma & & & & & & 1 & & & & 4 \\
\hline Ovarian cancer & & & & & & & & & & 2 \\
\hline Gangrene of lower extremities & & & & & & 1 & 1 & 1 & 3 & 2 \\
\hline
\end{tabular}

Fatty infiltration of the liver, which occurs in the severe insulin-deficient conditions, was most frequent in the younger cases and it decreased with age. This phenomenon was due to the fact that the coma was the common cause of death in diabetic infants. Cirrhosis of the liver and hepatic carcinoma were less in female cases. In this series, gall stone was seen only in $5.5 \%$ and the percentage was a little higher in females.

The atrophy of the pancreas was rather common in this series. The incidence of this finding fluctuated between 43 and $12 \%$ and it was frequent in infant cases. 


\begin{tabular}{|c|c|c|c|c|c|c|c|c|c|c|c|c|}
\hline \multicolumn{2}{|c|}{ 50-59 } & \multicolumn{2}{|c|}{$60-69$} & \multicolumn{2}{|c|}{$70-79$} & \multicolumn{2}{|c|}{$80-89$} & \multicolumn{2}{|c|}{$90-$} & \multicolumn{3}{|c|}{ Total } \\
\hline $\mathbf{M}$ & $\mathbf{F}$ & $\mathbf{M}$ & $\mathrm{F}$ & $\mathbf{M}$ & $\mathrm{F}$ & $\mathbf{M}$ & $\mathbf{F}$ & $\mathbf{M}$ & $\mathbf{F}$ & Male & Female & Total \\
\hline 372 & 243 & 588 & 424 & 304 & 210 & 54 & 32 & 1 & 2 & 1582 & 1172 & 2754 \\
\hline 1 & 2 & & 1 & & 1 & & & & & 1 & 4 & 5 \\
\hline 28 & 28 & 41 & 23 & 15 & 14 & 3 & & & 2 & 114 & 97 & 211 \\
\hline 3 & 3 & 3 & 4 & 1 & 3 & & & & & 8 & 14 & 22 \\
\hline 2 & 2 & 2 & 1 & & 2 & & & 1 & & 6 & 7 & 13 \\
\hline 7 & 7 & 6 & 9 & & 4 & & & & & 15 & 24 & 39 \\
\hline 20 & 11 & 31 & 22 & 14 & 12 & 1 & 3 & 1 & & 76 & 58 & 134 \\
\hline & & & & & & & 1 & & & & 1 & 1 \\
\hline 5 & 5 & 10 & 15 & 4 & 4 & 2 & 1 & & & 23 & 30 & 53 \\
\hline 16 & 10 & 27 & 17 & 6 & 5 & & 1 & & & 64 & 46 & 110 \\
\hline 5 & 2 & 10 & 7 & 3 & 1 & & & & & 23 & 22 & 45 \\
\hline 19 & 10 & 21 & 14 & 7 & 4 & 1 & & & & 62 & 41 & 103 \\
\hline 1 & 13 & 3 & 18 & 6 & 5 & & & & & 19 & 43 & 62 \\
\hline 4 & 3 & 8 & 11 & 2 & 2 & 1 & 1 & & & 16 & 21 & 37 \\
\hline 54 & 42 & 96 & 82 & 49 & 34 & 15 & 5 & & 1 & 251 & 211 & 462 \\
\hline 16 & 32 & 47 & 40 & 22 & 22 & 4 & 5 & & & 98 & 110 & 208 \\
\hline 93 & 69 & 150 & 123 & 57 & 45 & 5 & 3 & 1 & 2 & 377 & 324 & 701 \\
\hline 2 & 8 & 2 & 10 & 6 & 5 & & & 1 & & 12 & 31 & 43 \\
\hline $2 \overline{2}$ & 33 & 38 & 63 & 24 & 35 & 2 & 7 & & & 98 & 182 & 280 \\
\hline 3 & 7 & 3 & 11 & 2 & 2 & 1 & & & & 11 & 22 & 33 \\
\hline 16 & 12 & 42 & 32 & 27 & 12 & 3 & 3 & & & 96 & 64 & 160 \\
\hline 1 & 2 & 4 & 1 & 4 & 2 & 2 & & & & 11 & 6 & 17 \\
\hline 1 & 2 & 4 & 3 & 4 & 1 & 1 & & & & 10 & 6 & 16 \\
\hline 15 & 19 & 21 & 56 & 21 & 29 & 3 & 4 & & & 69 & 143 & 212 \\
\hline 2 & & 4 & & 2 & & & 1 & & & 8 & 1 & 9 \\
\hline 14 & 8 & 11 & 7 & 5 & 4 & $\mathbf{1}$ & 1 & & & 45 & 30 & 75 \\
\hline 4 & 3 & 2 & 1 & 1 & & & & & & 8 & 7 & 15 \\
\hline 4 & 2 & 3 & 3 & & 3 & & & & & 7 & 10 & 17 \\
\hline 2 & & 5 & & 3 & & 3 & & & & 14 & & 14 \\
\hline 8 & & 20 & & 20 & & 4 & & & & 57 & & 57 \\
\hline 3 & & 3 & & 5 & & 2 & & & & 15 & & 15 \\
\hline & 6 & & 11 & & 3 & & & & & & 20 & 20 \\
\hline & 13 & & 21 & & 13 & & 2 & & & & 56 & 56 \\
\hline & 1 & & 7 & & 5 & & 2 & & & & 20 & 20 \\
\hline & 3 & & 2 & & & & & & & & 7 & 7 \\
\hline 5 & 10 & 10 & 5 & 4 & & & 1 & & & 23 & 20 & 43 \\
\hline
\end{tabular}

Fibrosis, cirrhosis of the pancreas and pancreatitis were present in $3.1,1.3$ and 4.0 $\%$, respectively. A decrease in number of the islets and atrophy of the islets were present in $7.6 \%$ and this percentage was high in the second and third decades of age as seen in Fig. 2. The incidence of the hyaline degeneration of the islets was high in the twenties and it decreased with age.

Diabetic glomerular sclerosis began to occur at the second decade of age and its incidence increased until the fifties. Papillary necrosis and pyelonephritis were about three times more frequent in females than in males. 
TABLE 5. Classification of the 3151 cases

\begin{tabular}{lrrrr}
\hline & Male & Female & Total & $\%$ \\
\hline Primary Diabetes & 1582 & 1172 & 2754 & 87.40 \\
Secondary Diabetes & 290 & 107 & 397 & 12.60 \\
Liver cirrhosis & 136 & 39 & 175 & 5.55 \\
Cancer of the pancreas & 66 & 30 & 96 & 3.05 \\
Pancreatitis & 20 & 5 & 25 & 0.79 \\
Hemochromatosis & 18 & 4 & 22 & 0.70 \\
Acromegaly & 1 & 8 & 9 & 0.29 \\
Cushing syndrome & 1 & 2 & 3 & 0.10 \\
Hyperthyroidism & 1 & 1 & 2 & 0.06 \\
Pheochromocytoma & 1 & 0 & 1 & 0.03 \\
Primary aldosteronism & 1 & 0 & 1 & 0.03 \\
Steroid diabetes & 45 & 18 & 63 & 2.00 \\
\hline
\end{tabular}

The atrophy of the adrenal gland was found in the first decade and its incidence decreased with age. Gangrene of the feet was present in 43 of the cases.

\section{B. Secondary diabetes}

Of the 3151 cases, $397(12.6 \%)$ were classified as secondary diabetes (Table 5). The prevalence of the secondary diabetes was $4.4 \%$ in the cases under twenty years, $6.3 \%$ in the twenties, $16.6 \%$ in the thirties, $18.5 \%$ in the forties, $15.6 \%$ in the fifties, $11.3 \%$ in the sixties, $9.6 \%$ in the seventies and $4.4 \%$ in the cases over 80 years.

The first ranking disease provoking the diabetic state was cirrhosis of the liver (5.5\%). Ninety-six cases had cancer of the pancreas (66 males and 30 females). The main tumor was present at the head of the pancreas in 47 cases, at the body in 8 cases, and at the tail in 12 cases. In 25 cases, their diabetic state was thought to be due to pancreatitis or pancreatic lithiasis. In this group, 20 were males and 5 were females, and 3 of these cases had diabetic glomerular sclerosis. Hemochromatosis was $0.7 \%$ of the total cases. Seven cases were under sixty years old and 7 cases were in the sixties.

In the 9 cases with acromegaly, 8 were females and 2 of them had the changes of diabetic glomerular sclerosis. Of the 3 cases with Cushing syndrome, 2 had basophil cell adenoma of the pituitary and 1 had adrenal carcinoma.

Sixty-three cases were classified as steroid diabetes. Their original diseases were leukemia in 24 cases, hypoplastic anemia in 18 cases, fibrosis of bone marrow in 2 cases, malignant lymphoma in 2 cases, hepatitis in 2 cases, bronchial asthma in 2 cases, etc.

\section{Discussion}

This study shows the prevalence of the cause of death in diabetic patients. As cases were collected from various clinics, the result of this study can be regarded as a general figure.

It is widely accepted that vascular complications occur frequently in diabetics. 
TABLE 6. Myocardial infarction and cerebral vascular accident in diabetics and in general population

\begin{tabular}{|c|c|c|c|c|c|c|c|c|c|}
\hline & \multicolumn{3}{|c|}{ Diabetic } & \multicolumn{3}{|c|}{ All registered cases } & \multicolumn{3}{|c|}{ General population* } \\
\hline & Male & Female & Total & Male & Female & Total & Male & Female & Total \\
\hline Total cases & 1582 & 1172 & 2754 & 76080 & 49994 & 126074 & 387716 & 324987 & 712703 \\
\hline Myocardial infarction & $\begin{array}{c}174 \\
(11.0 \%)\end{array}$ & $\begin{array}{c}122 \\
(10.4 \%)\end{array}$ & $\begin{array}{c}296 \\
(10.7 \%)\end{array}$ & $\begin{array}{c}2041 \\
(2.7 \%)\end{array}$ & $\begin{array}{l}1001 \\
(2.0 \%)\end{array}$ & $\begin{array}{l}3042 \\
(2.4 \%)\end{array}$ & $\begin{array}{c}22291 \\
(5.7 \%)\end{array}$ & $\begin{array}{l}16600 \\
(5.1 \%)\end{array}$ & $\begin{array}{r}38891 \\
(5.496)\end{array}$ \\
\hline Cerebral infarction & $\begin{array}{c}213 \\
(13.4 \%)\end{array}$ & $\begin{array}{c}169 \\
(14.4 \%)\end{array}$ & $\begin{array}{c}382 \\
(13.9 \%)\end{array}$ & $\begin{array}{c}3527 \\
(4.696)\end{array}$ & $\begin{array}{c}2337 \\
(4.6 \%)\end{array}$ & $\begin{array}{c}5864 \\
(4.6 \%)\end{array}$ & $\begin{array}{c}30586 \\
(7.9 \%)\end{array}$ & $\begin{array}{c}28384 \\
(8.79)\end{array}$ & $\begin{array}{c}58970 \\
(8.3 \%)\end{array}$ \\
\hline Cerebral hemorrhage & $\begin{array}{c}97 \\
(6.1 \%)\end{array}$ & $\begin{array}{c}60 \\
(5.1 \%)\end{array}$ & $\begin{array}{c}157 \\
(5.7 \%)\end{array}$ & $\begin{array}{c}3567 \\
(4.7 \%)\end{array}$ & $\begin{array}{l}1810 \\
(3.6 \%)\end{array}$ & $\begin{array}{l}5377 \\
(4.2 \%)\end{array}$ & $\begin{array}{r}46782 \\
(12.0 \%)\end{array}$ & $\begin{array}{r}38626 \\
(11.9 \%)\end{array}$ & $\begin{array}{r}85408 \\
(11.9 \%)\end{array}$ \\
\hline $\begin{array}{l}\text { Infarction/ } \\
\text { Hemorrhage }\end{array}$ & 2.2 & 2.8 & 2.4 & 1.0 & 1.3 & 1.1 & 0.6 & 0.7 & 0.7 \\
\hline
\end{tabular}

* Reported from the Welfare Ministry in 1971.

The percentage of myocardial infarction and that of cerebral vascular accident in this series are compared with those of the total cases registered in the Annual Reports (1965-1970) and also with the statistics of mortality reported by the Welfare Ministry of Japan (Table 6). The incidence of myocardial infarction is significantly higher in the diabetic group than in the other groups and this is the same for cerebral infarction. The incidence of cerebral hemorrhage, however, is not different from the other groups. The ratio of cerebral infarction to cerebral hemorrhage is significantly greater in the diabetic group than in the other groups $(\mathrm{P}<0.005)$. The mechanism of occurrence of cerebral infarction is different from that of the hemorrhage. It can be said, therefore, that cerebral infarction occurs easily in diabetics, in other words, the abnormalities occurring in diabetics including hyperlipemia are favoring cerebral infarction.

The first ranking cause of death in diabetic patients is ischemic heart disease in the United States (Bell 1960; Warren et al. 1966; Marble et al. 1971) and this makes a striking contrast to the figures in the present series in which the ischemic heart disease is low. What is the cause of this difference? In our previous report, it was clearly shown that the mortality of arteriosclerotic heart disease among many countries was closely related to the average consumption of fat ( $\mathrm{g} / \mathrm{man} /$ day) $(\mathrm{P}<0.01)$ and also to that of protein $(\mathrm{P}<0.05)$, but that it is not related to that of carbohydrate $(\mathrm{P}>0.10)$. The mortality of diabetes and the consumption of nutrients among the countries also showed a similar relationship (Goto 1963). In Japan, the average consumption of fat in 1969 is $45 \mathrm{~g} / \mathrm{man} /$ day and those of protein and carbohydrate are 77 and $376 \mathrm{~g} / \mathrm{man} /$ day, respectively. The consumption of fat in this country has increased during the last twenty years, but it is still very low as compared with that in the United States. It is well known that American people are more obese than Japanese and the serum lipids level of the Japanese people is lower than that of Americans. This may be one of the reasons for the low incidence of ischemic heart disease in Japanese diabetics, and if this speculation 
is acceptable, the restriction of fat may be necessary for diabetics and a normalization of serum lipids may be important in the management of diabetes.

The result of the present study revealed that the diabetic nephropathy was the first ranking cause of death in Japan. This is quite different from that of the United States. Our report on renal biopsy study showed that $45.1 \%$ of the 206 diabetic in-patients had diabetic glomerular changes and $20.4 \%$ of them had a nodular type lesion. The prevalence of this change became higher with age and also with duration of the disease (Yamauchi et al. 1973). The incidence of diabetic glomerular sclerosis in this series is $25.4 \%$ and this figure is less than that of Bell's series (Bell 1960). Therefore, the high ranking of diabetic nephropathy as the cause of death in Japan will be simply due to the lower incidence of ischemic heart disease. As the diabetic nephropathy is less frequent in China (Chung et al. 1963) and Formosa (Tsai 1963), the race difference is unlikely to be a cause.

The atrophy of the pancreas was described in $15.6 \%$ of the total cases and this finding was most frequent in the first decade and the percentage fluctuated between 12 to 20 after the third decade. This result is consistent with the report that the weight of the pancreas is sometimes small in juvenile diabetics and that there is no significant difference in weight of the pancreas between adult onset diabetes and nondiabetics (Lazarus and Volk 1962). Although the cases with hypoplasia of the pancreas do not always have diabetes, the atrophy of the pancreas may play some role in the occurrence of diabetes. Unfortunately, there is no description of the weight of the pancreas in the records, so an attempt of further quantitative study is impossible.

In this study, $12.6 \%$ of the cases were classified as secondary diabetes. In spite of a careful examination, the underlying diseases provoking diabetic state are sometimes overlooked. For example, chronic pancreatitis without attacks is not diagnosed unless the $\mathrm{X}$-ray examinations or the function tests of exocrine pancreas are made as a routine examination for diabetes. Pheochromocytoma is sometimes diagnosed as a case with two common diseases, diabetes and hypertension, if further endocrinological examinations are not made. The figures obtained in the autopsy cases, therefore, may be an ideal one showing the percentage of primary and secondary diabetes, although some of the secondary diabetes are cured completely by operation and these operated cases are not included in this study.

\section{References}

1) Bell, E.T. (1960) Diabetes Mellitus. A Clinical and Pathological Study of 2,529 Cases. Thomas, Springfield, pp. 24-26.

2) Chung, H.L., Ch'eng, S.P., Ch'iu, C.L., Chu, P.J., Lin, Y.S., Tai, J.H., Shen, T.M. \& Chu, J.H. (1963) Cardiovascular diseases in diabetes mellitus. Chin. med. J., 82, 208-220.

3) Fitz, R. \& Murphy, W.P. (1924) The cause of death in diabetes mellitus. Amer. $J$. med. Sci., 168, 313-325.

4) Flynn, J.M. (1935) The changing cause of death in diabetes mellitus. Amer. J. med. Sci., 189, 157-162.

5) Goto, Y. (1963) Carbohydrate and fat in the treatment diet for diabetics and patients 
with liver disease. J. Jap. Soc. intern. Med. (Jap.), 52, 748-753.

6) Goto, Y. (1973) Natural history of diabetes mellitus. Diabetes J., 1, 4-11.

7) Goto, Y. \& Fukuhara, N. (1968) Cause of death in 933 diabetic autopsy cases. $J$. Jap. Diab. Soc., 11, 197-206.

8) John, H.J. (1937) Causes of mortality among diabetics. Amer. J. dig. Dis., 4, 291294.

9) John, H.J. (1950) Statistical study of 6,000 cases of diabetes. Ann. intern. Med., 33, 925-940.

10) Kessler, I.I. (1971) Mortality experience of diabetic patients. A twenty-six year follow-up study. Amer. J. Med., 51, 715-724.

11) Kuriki, A. (1973) Statistical study on diabetes in Aizu area. J. Jap. Diab. Soc., 16, 100 ,

12) Lazarus, S.S. \& Volk, B.W. (1962) The Pancreas in Human and Experimental Diabetes. Grune \& Stratton, New York, pp. 196-197.

13) Lyon, D.M. \& Lyon, M.M. (1930) The cause of death among diabetics. Lancet, 2, 293-295.

14) Marble, A., White, P., Bradley, R.F. \& Krall, L.P. (1971) Joslin's Diabetes Mellitus. 11th ed., Lea \& Febiger, Philadelphia, p. 225.

15) Munz, W. (1960) Häufigkeit und zeitliches Auftreten der Organmanifestationen beim Diabetes mellitus. Schweiz. med. Wschr., 90, 241-245.

16) Robbins, S.L. \& Tucker, A.W. (1944) The cause of death in diabetes. A report of 307 autopsied cases. New Engl. J. Med., 231, 865-868.

I7) Schöfling, K. \& Graeve, R. (1956) Ueber die Todesursachen bei der Zuckerkrankheit. Medizinische, 16, 627-631.

18) Sevringhaus, E.L. (1931) A study of five hundred diabetics. Amer. J. med. Sci., 182, 311-319.

19) Tobler, R. (1954) Autoptische Beobachtungen an 300 Diabetikern. Schweiz. med. $W s c h r ., 84,1213-1216$.

20) Tsai, S.H. (1963) Clinical studies on cardiovascular diseases of diabetes in Taiwan. $J$. Formasan med. Ass., 62, 1-12.

21) Warren, S., LeCompte, P.M. \& Legg, M.A. (1966) The Pathology of Diabetes Mellitus. 4th ed., Lea \& Febiger, Philadelphia, pp. 512-513.

22) Yamagata, S., Goto, Y., Anzai, M., Kawashima, S. \& Yamauchi, Y. (1967) Studies on the cause of death in diabetics. J. Jap. Diab. Soc., 10, 471.

23) Yamauchi, Y., Suzuki, J., Ohneda, A., Yamagata, S. \& Goto, Y. (1973) Onset and progress of diabetic glomerulosclerosis. Tohoku J. exp. Med., 109, 385-406. 